\title{
TESTS OF SIGNIFICANCE IN A $2 \times 2$ CONTINGENCY TABLE: EXTENSION OF FINNEY'S TABLE
}

\author{
COMPUTED BY R. LATSCHA \\ Institute of Actuarial Science, University of Berne \\ EDITORIAL FOREWORD
}

Finney (1948) has given a table which may be used to test the significance of the deviation from proportionality in any $2 \times 2$ contingency table having both the frequencies in one of its margins less than or equal to 15. The table printed below extends the range of Finney's table up to marginal frequencies of 20 . As the interpretation and usea of the new table are exactly similar to those of the 1948 table, only a brief introductory statement is required.*

Using Finney's notation, the contingency table should be arranged in the form

\begin{tabular}{|c|c|c|c|}
\hline & \multicolumn{2}{|c|}{ Number of } & \multirow{2}{*}{ Total } \\
\hline & Successed & Failures & \\
\hline \multirow[t]{2}{*}{$\begin{array}{l}\text { Series I } \\
\text { Series II }\end{array}$} & $\begin{array}{l}a \\
b\end{array}$ & $\begin{array}{l}A-a \\
B-b\end{array}$ & $\begin{array}{l}A \\
B\end{array}$ \\
\hline & $r=a+b$ & $A+B-a-b$ & $A+B$ \\
\hline
\end{tabular}

where series $\mathrm{I}$ is defined to be that which makes $A \geqslant B$, and the type of observation conventionally regarded as a 'success' is that which makes $a / A \geqslant b / B$. The table of significance levels is arranged in sections according to the value of $A$; the sections for $A=9(1) 15$ were given by Finney, while those for $A=16(1) 20$ computed by Latscha are printed below.

For given data, the table is entered in the section for $A$, the subsection for $B$ and the line for $a$; then the main body of the table shows in bold type the appropriate significance points for $b$. Thus if the observed value of $b$ is equal to or less than the bold integer in the column headed $0 \cdot 05,0 \cdot 025,0.01$ or 0.005 , then $a / A$ is significantly grester then $b / B$ (singletail test) at these probability levels. On the other hand, for the two-tail test, if $b$ is equal to or less than the integer in a given column, $a / A$ is significantly different from $b / B$ at a probability level equal to twice the figure heading that column, i.e. at the $0 \cdot 10,0 \cdot 05$, 0.02 and 0.01 levels, respectively. A dash, or absence of an entry, for some combination of $A, B$ and $a$ indicates that no $2 \times 2$ table in that class can show a significant effect at that level.

Owing to the discontinuous character of the hypergeometric distribution, the conditional probability that, for a given value of $a+b, b$ will be equal to or less than the value specified in bold type will generally be less, and often very considerably less, than that shown at the head of the column; the true probabilities are given in small type.

* Copies of Finney's table are available as a Biometrika 'eparate' and the present extension will be made available in aimilar form. Finney's table, but not the extension, is included in the new Biometrita Tables for Statioticians now at Press. 
As an illustration, we may use Lange's data on criminality among twin brothers or sisters of criminals (Fisher, 1946, §21.01). This example was taken by Finney (1948), but as $A>15$ he used it to show how his table could be extended under certain conditions. As $A \leqslant 20$, direct entry is now possible in Laticha's table.

The contingency table shows the number of twin brother or sisters of criminals who had also been convicted of crime, classing separately monozygotic and dizygotic (but likesexed) twins:

\begin{tabular}{|c|c|c|c|}
\hline & Not convictod & Convicted & Total \\
\hline $\begin{array}{l}\text { Dizygotic } \\
\text { Monozygotic }\end{array}$ & $\begin{array}{r}15(=a) \\
3(=b)\end{array}$ & $\begin{array}{c}2 \\
10\end{array}$ & $\begin{array}{c}17(=A) \\
13(=B)\end{array}$ \\
\hline Total & 18 & 12 & 30 \\
\hline
\end{tabular}

Following the rule given above, the letters $A, B, a$ and $b$ are associated with the observed frequencies as shown. The null-hypothesis is that the twin of a criminal is no more likely to be convicted of crime if the twinning is monozygotic than if it is dizygotic. If the only deviation from the hypothesis which we are prepared to consider is that monozygotic twing behave more similarly than dizygotic, a aingle-tail test will be appropriate and we shall ask whether $a / A=15 / 17$ is significantly greater than $b / B=3 / 13$.

Turning to the appropriate section of the table with $A=17, B=13$ and $a=15$ we find that the observed value of $b=3$ is significant at the $0.5 \%$ level, since it is less than 4 , the last entry in the row of bold figures.

The figure in small type following $b=4$ indicates that for a contingency table with marginal frequencies

$$
A=17, \quad B=13, \quad r=a+b=15+4=19, \quad A+B-a-b=11,
$$

the conditional probability of an arrangement within the table with $b \leqslant 4$ is 0.002 on the null hypothesis of independence. The probability that $b \leqslant 3$ within the observed table (having $a+b=18$ ) is not recorded, but is $<0.002$.

As far as possible, checks on the internal consistency of the table have been made as well as comparisons with the more extensive tables for the special case $A=B$ published by Swaroop (1950).

\section{REFERENCES}

Finntey, D. J. (1948). Biometrika, 35, 148.

Fisher, R. A. (1946). Statistical Methods for Research Workers, 10th ed. Edinburgh: Oliver and Boyd. Swaroop, S. (1950). Indian Med. Res. Mem., no. 35. 
Signifloance tests in a $2 \times 2$ contingenoy table

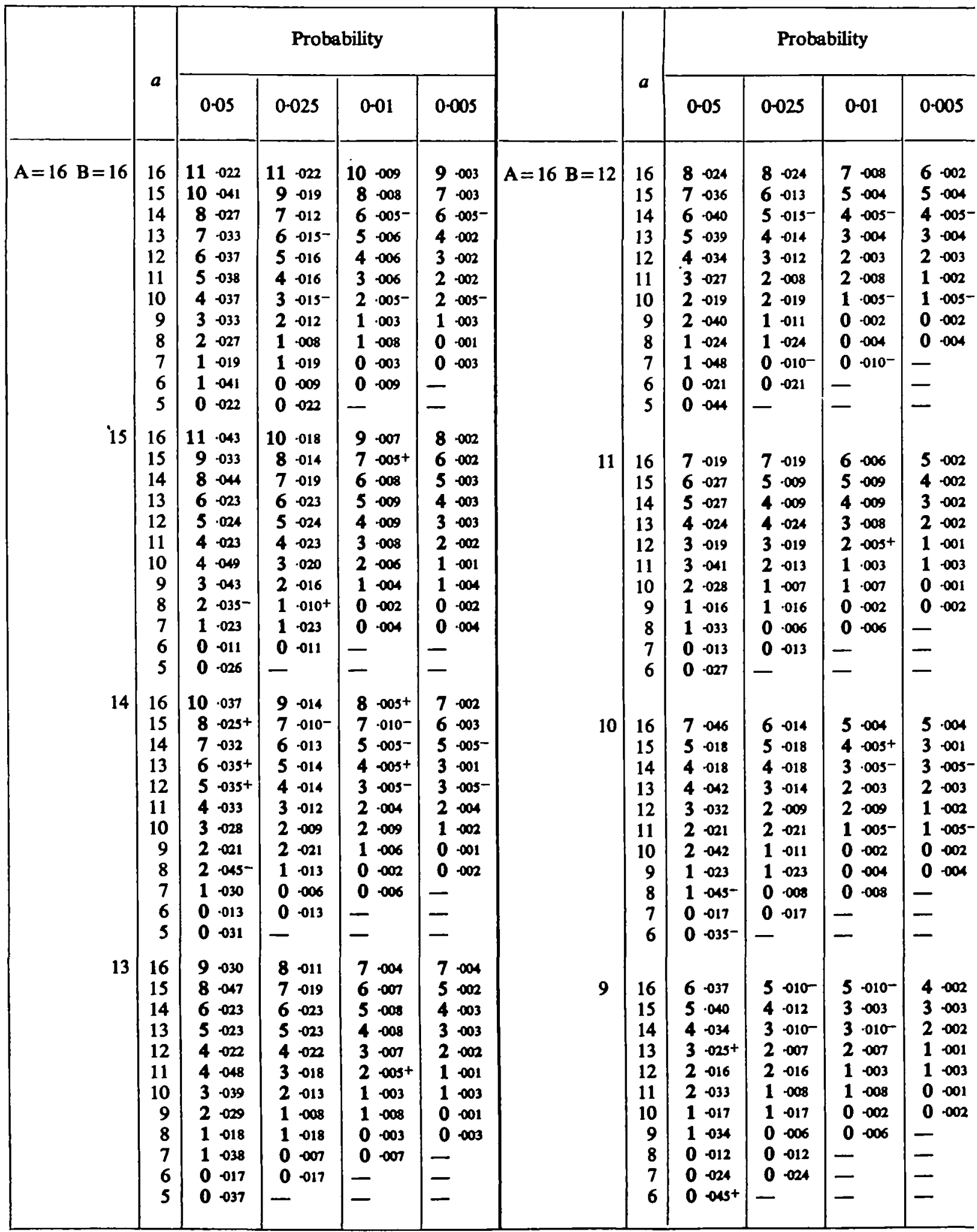

The table shows:

(1) In bold type, for given $A, B$ and $a$, the value of $b(<a)$ which is just significant at the probability lev quoted (single-tail test).

(2) In amall type, for given $A, B$ and $r=a+b$, the exact probability (if there is independence) that $b$ is equal $t$ or lese than the integer ahown in bold type. 
Signifloance testo in a $2 \times 2$ contingenoy wble (oontinued)

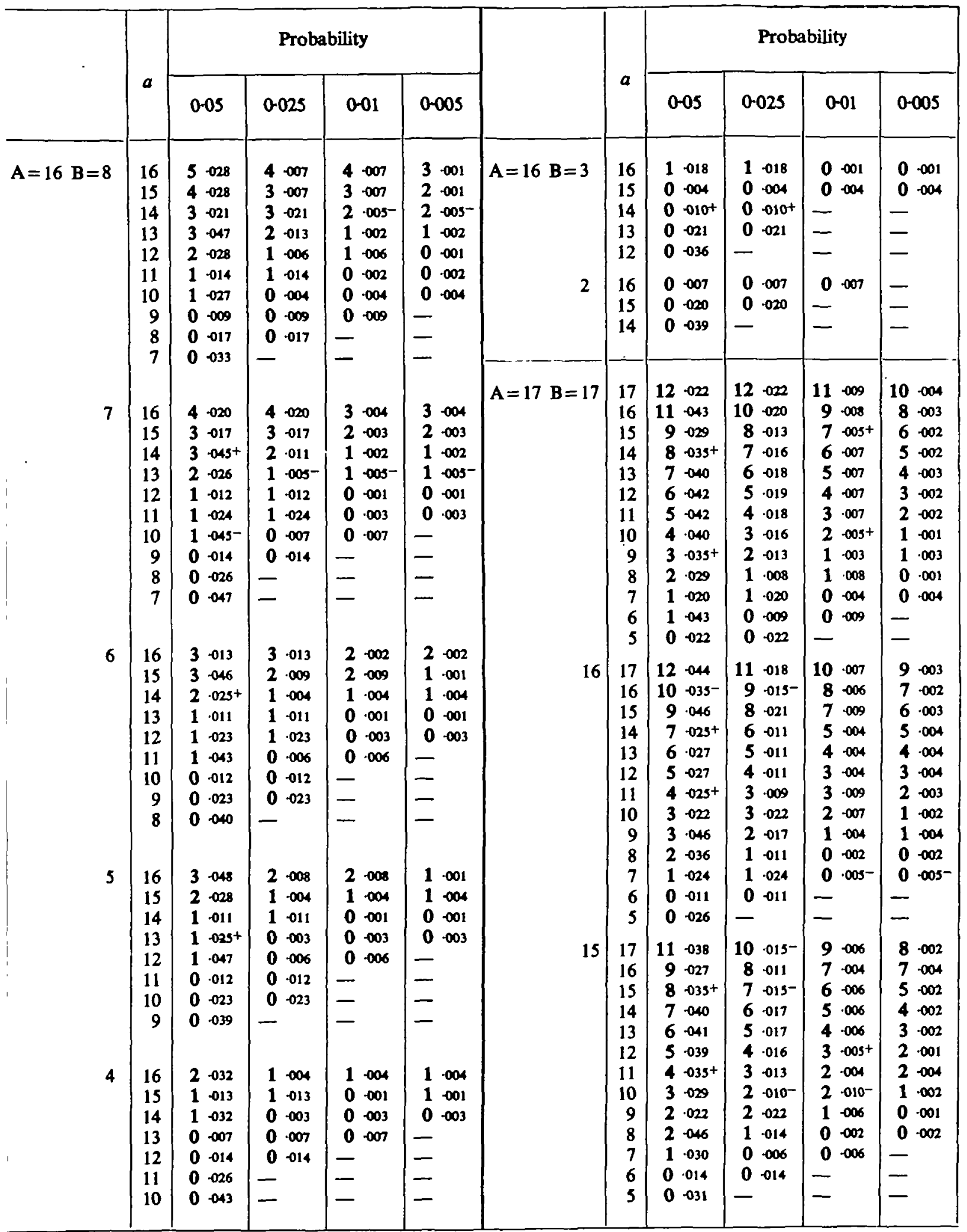


Significance tests in a $2 \times 2$ contingency table (continued)

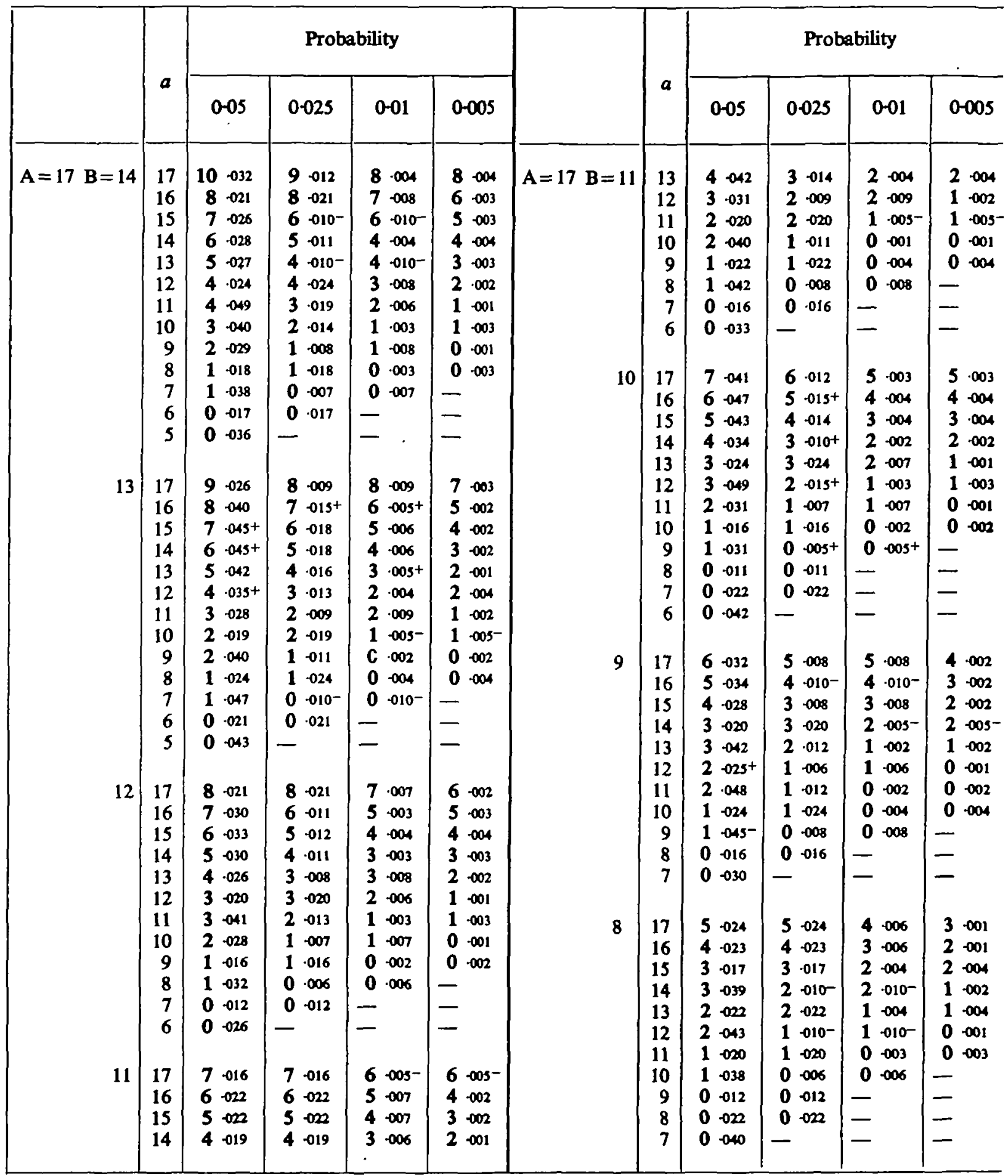

The table shows:

(1) In bold type, for given $A, B$ and $a$, the value of $b(<a)$ which is just significant at the probability leve: quoted (Bingle-tail test).

(2) In small type, for given $A, B$ and $r=a+b$, the exact probability (if there is independence) that $b$ is equal to or leses than the integer shown in bold type. 
Signifloance teste in $a 2 \times 2$ contingency table (continued)

\begin{tabular}{|c|c|c|c|c|c|c|c|c|c|c|c|c|}
\hline & & & Proba & bility & & & & & Proba & bility & & \\
\hline & & 0.05 & $0-025$ & $0-01$ & $0-005$ & & & $0-05$ & $0-025$ & 0.01 & $0-0$ & 205 \\
\hline$A=17 \quad B=7$ & $\begin{array}{r}17 \\
16 \\
15 \\
14 \\
13 \\
12 \\
11 \\
10 \\
9 \\
8 \\
17 \\
16 \\
15 \\
14 \\
13 \\
12 \\
11 \\
10 \\
9 \\
17 \\
16 \\
15 \\
14 \\
13 \\
12 \\
11 \\
17 \\
16 \\
15 \\
14 \\
13 \\
12 \\
17 \\
16 \\
15\end{array}$ & 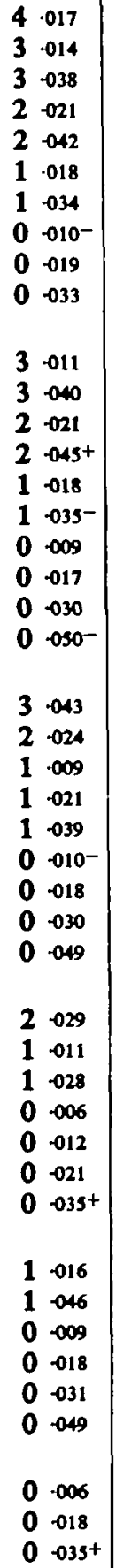 & 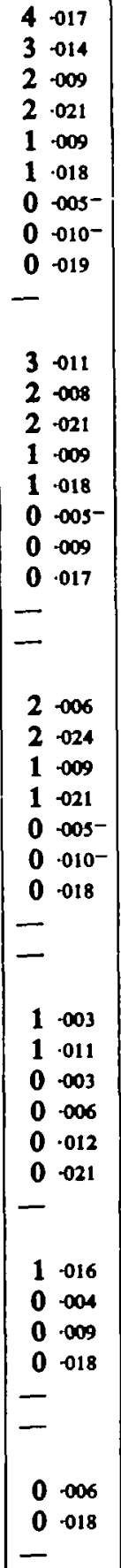 & 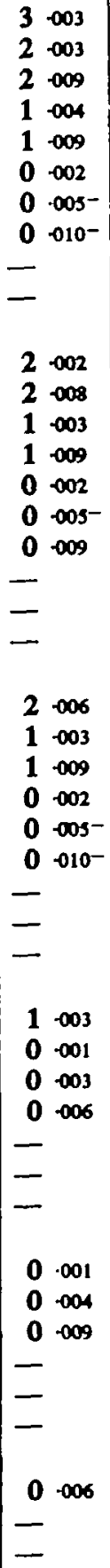 & 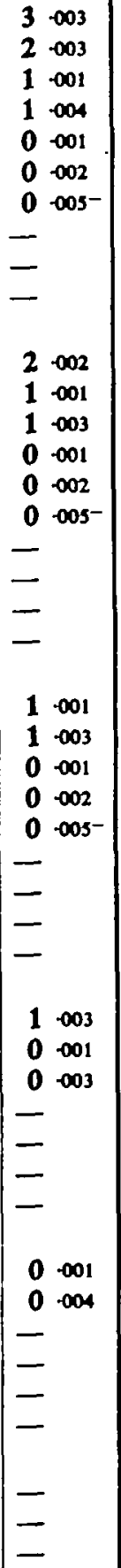 & $A=18 \quad B=18$ & $\begin{array}{r}18 \\
17 \\
16 \\
15 \\
14 \\
13 \\
12 \\
11 \\
10 \\
9 \\
8 \\
7 \\
6 \\
5 \\
18 \\
17 \\
16 \\
15 \\
14 \\
13 \\
12 \\
11 \\
10 \\
9 \\
8 \\
7 \\
6 \\
5 \\
18 \\
17 \\
16 \\
15 \\
14 \\
13 \\
12 \\
11 \\
10 \\
9 \\
8 \\
7 \\
6 \\
5 \\
18 \\
17 \\
16 \\
15 \\
14 \\
13\end{array}$ & 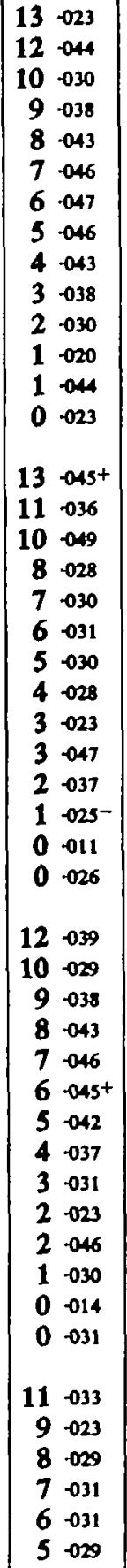 & 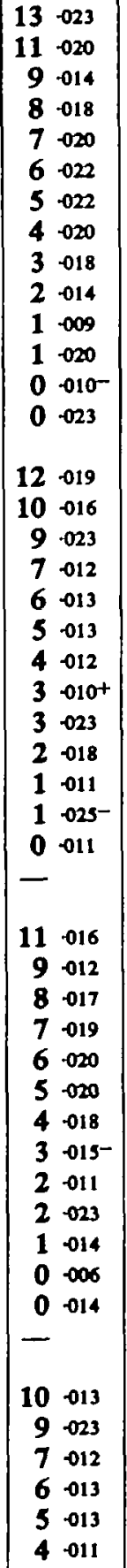 & 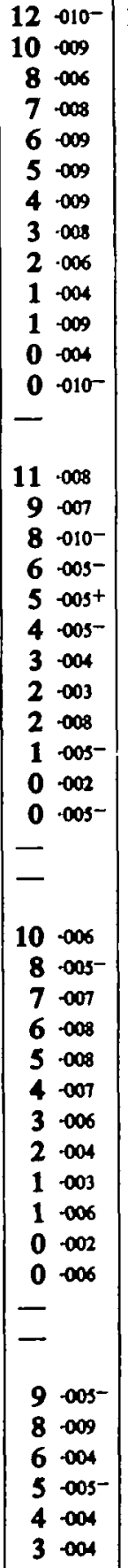 & 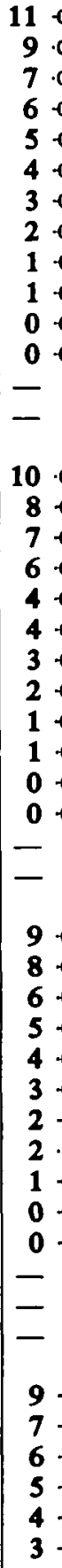 & $\begin{array}{l}-003 \\
.002 \\
-004 \\
.005- \\
.002 \\
.005- \\
.004 \\
.003 \\
-002 \\
.005- \\
.002 \\
.005^{-}\end{array}$ \\
\hline
\end{tabular}


Signifroance tests in a $2 \times 2$ contingency table (continued)

\begin{tabular}{|c|c|c|c|c|c|c|c|c|c|c|c|c|}
\hline & & \multicolumn{4}{|c|}{ Probability } & & & \multicolumn{5}{|c|}{ Probability } \\
\hline & & 0.05 & 0.025 & $0-01$ & $0-005$ & & & $0-05$ & 0.025 & $0-01$ & & -005 \\
\hline$A=18 \quad B=15$ & $\begin{array}{r}12 \\
11 \\
10 \\
9 \\
8 \\
7 \\
6 \\
5 \\
\\
18 \\
17 \\
16 \\
15 \\
14 \\
13 \\
12 \\
11 \\
10 \\
9 \\
8 \\
7 \\
6 \\
5 \\
\\
18 \\
17 \\
16 \\
15 \\
14 \\
13 \\
12 \\
11 \\
10 \\
9 \\
8 \\
7 \\
18 \\
17 \\
16 \\
14 \\
11\end{array}$ & 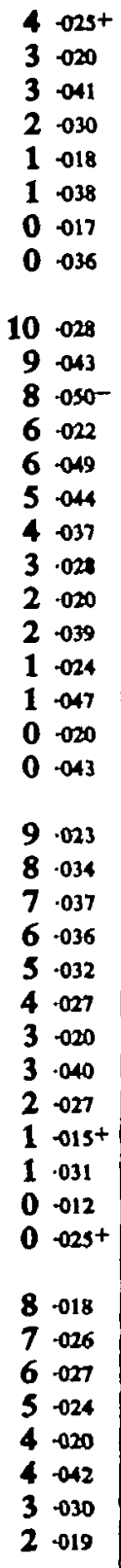 & 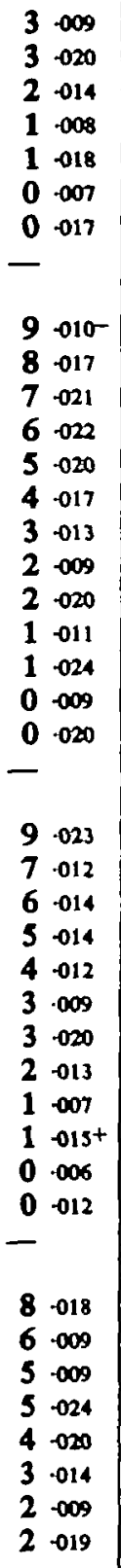 & 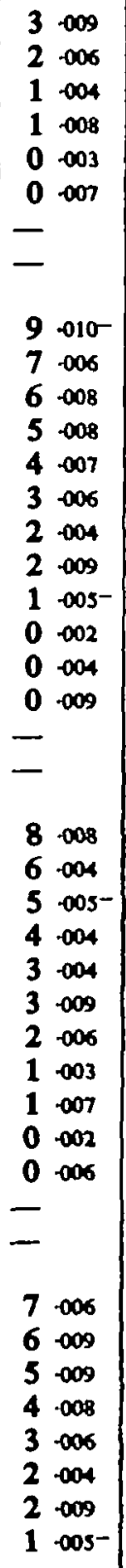 & 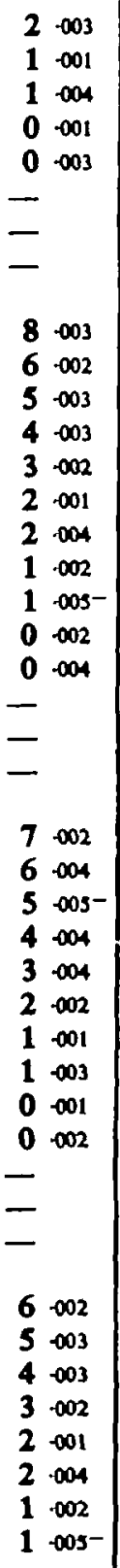 & $A=18 \quad B=12$ & $\begin{array}{r}10 \\
9 \\
8 \\
7 \\
6 \\
\\
18 \\
17 \\
16 \\
15 \\
14 \\
13 \\
12 \\
11 \\
10 \\
9 \\
8 \\
7 \\
6 \\
\\
18 \\
17 \\
16 \\
15 \\
14 \\
13 \\
12 \\
11 \\
10 \\
9 \\
8 \\
7 \\
6 \\
18 \\
17 \\
16 \\
15 \\
14 \\
13 \\
12 \\
11 \\
10 \\
7\end{array}$ & 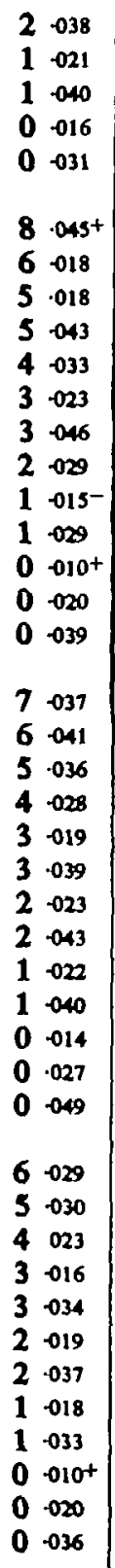 & 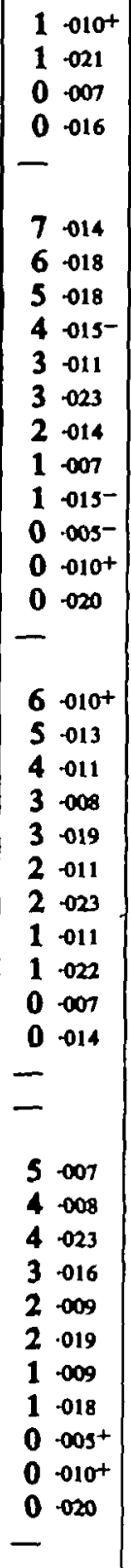 & 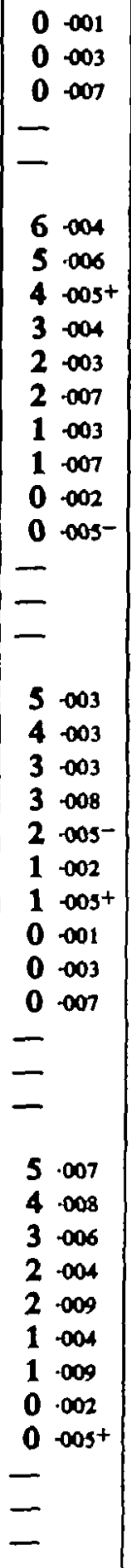 & $\begin{array}{c}0 \\
0 \\
- \\
- \\
- \\
6 \\
4 \\
3 \\
3 \\
2 \\
1 \\
1 \\
0 \\
0 \\
0 \\
- \\
- \\
- \\
5 \\
4 \\
3 \\
2 \\
2 \\
1 \\
0 \\
0 \\
0 \\
- \\
- \\
-\end{array}$ & 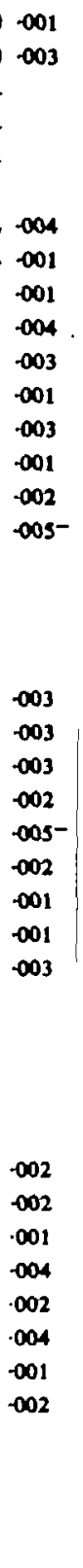 \\
\hline
\end{tabular}

The table shows:

(1) In bold type, for given $A, B$ and $a$, the value of $b(<a)$ which is just significant at the probability level quoted (single-tail test).

(2) In small type, for given $A, B$ and $r=a+b$, the exact probability (if there is independence) that $b$ is equal to or lese than the integer ahown in bold type. 
Signifloance tests in a $2 \times 2$ contingency table (continued)

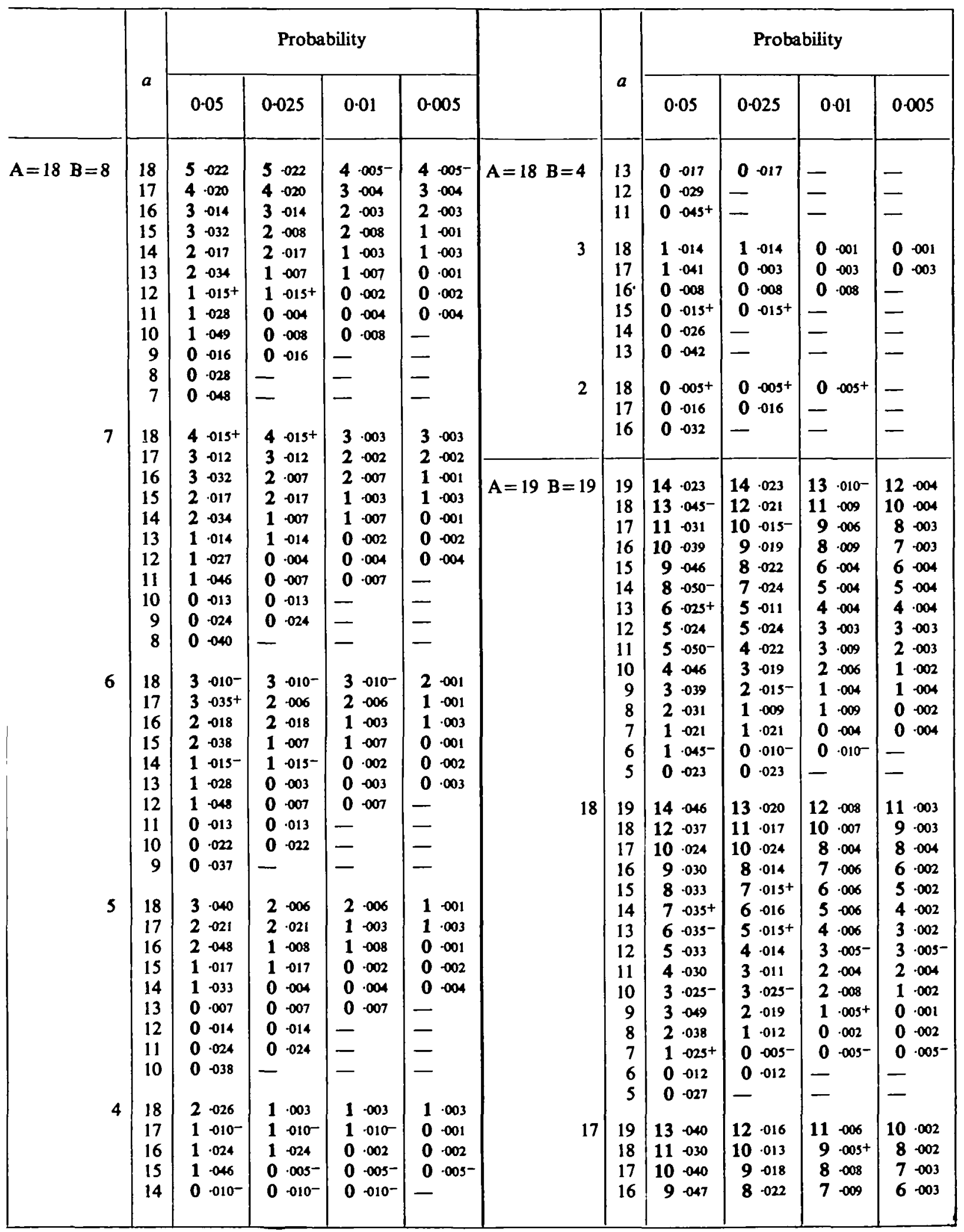


Significance tests in a $2 \times 2$ contingency table (continued)

\begin{tabular}{|c|c|c|c|c|c|c|c|c|c|c|c|}
\hline & & & Proba & lity & & & & & Prol & ility & \\
\hline & & 0.05 & 0025 & 001 & 0.005 & & & 0.05 & 0.025 & 0.01 & 0.005 \\
\hline$A=19 \quad B=17$ & 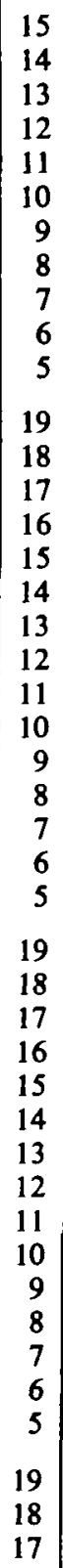 & 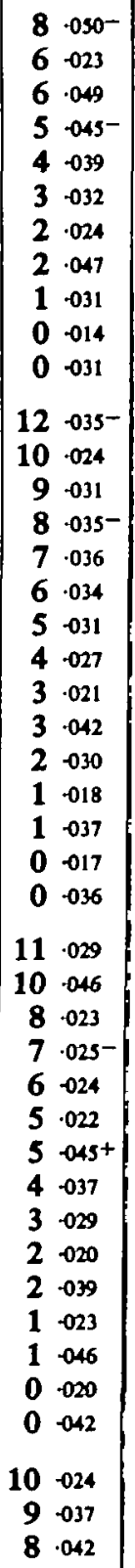 & 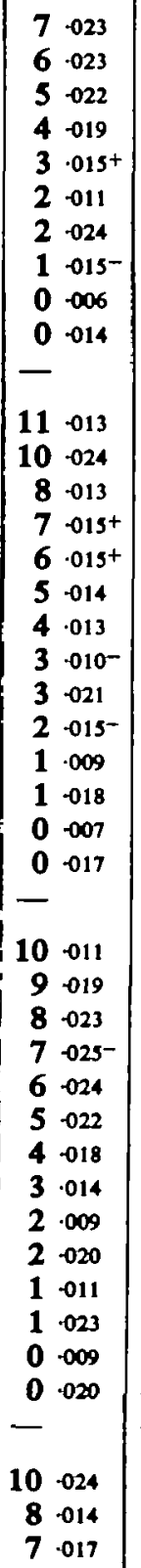 & 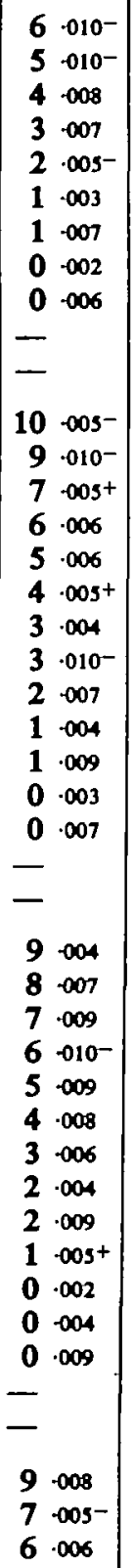 & 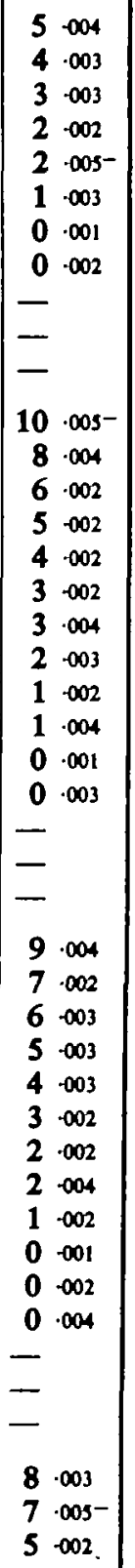 & 12 & $\begin{array}{r}16 \\
15 \\
14 \\
13 \\
12 \\
11 \\
10 \\
9 \\
8 \\
7 \\
6 \\
5 \\
19 \\
18 \\
17 \\
16 \\
15 \\
14 \\
13 \\
12 \\
11 \\
10 \\
9 \\
8 \\
7 \\
6 \\
19 \\
18 \\
17 \\
16 \\
15 \\
14 \\
13 \\
12 \\
11 \\
10 \\
9 \\
8 \\
7 \\
6 \\
19 \\
18 \\
17 \\
\end{array}$ & 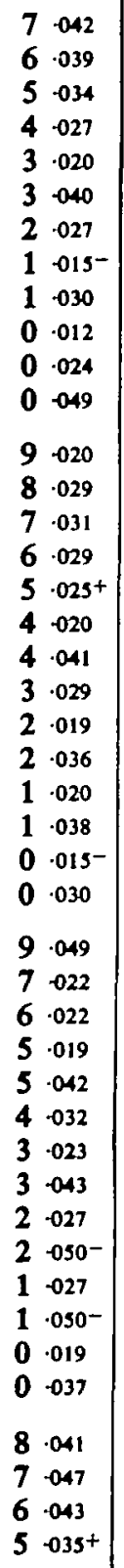 & 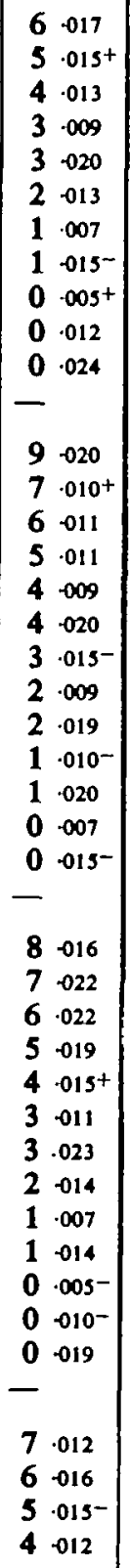 & 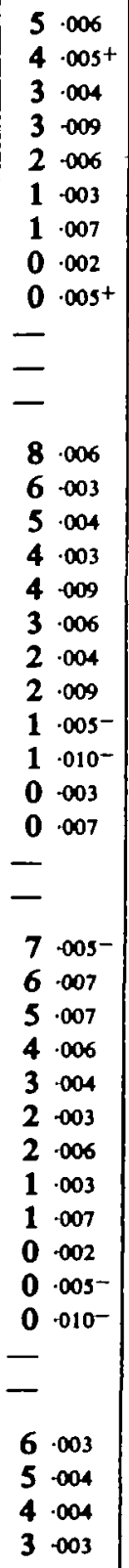 & $\begin{array}{ll}4 & \cdot 002 \\
3 & \cdot 001 \\
3 & \cdot 004 \\
2 & \cdot 003 \\
1 & \cdot 001 \\
1 & \cdot 003 \\
0 & \cdot 001 \\
0 & \cdot 002 \\
- & \\
- & \\
- & \\
- & \\
& \\
7 & \cdot 002 \\
6 & \cdot 003 \\
5 & \cdot 004 \\
4 & \cdot 003 \\
3 & \cdot 003 \\
2 & \cdot 002 \\
2 & \cdot 004 \\
1 & \cdot 002 \\
1 & \cdot 005- \\
0 & \cdot 001 \\
0 & \cdot 003 \\
- & \\
- & \\
- & \\
7 & \cdot 005- \\
5 & \cdot 002 \\
4 & \cdot 002 \\
3 & \cdot 002 \\
3 & \cdot 004 \\
2 & \cdot 003 \\
1 & \cdot 001 \\
1 & \cdot 003 \\
0 & \cdot 001 \\
0 & \cdot 002 \\
0 & \cdot 005- \\
- & \cdot 003 \\
- & \cdot 004 \\
- & \cdot 004 \\
3 & \cdot 003\end{array}$ \\
\hline
\end{tabular}

The teble shows:

(1) In bold type, for given $A, B$ and $a$, the value of $b(<a)$ which is just significant at the probability level quoted (single-tail test).

(2) In amall type, for given $A, B$ and $r=a+b$, the exact probability (if there is independence) that $b$ is equal to or less than the integer shown in bold type. 
Significance testo in a $2 \times 2$ contingenoy table (oontinuod)

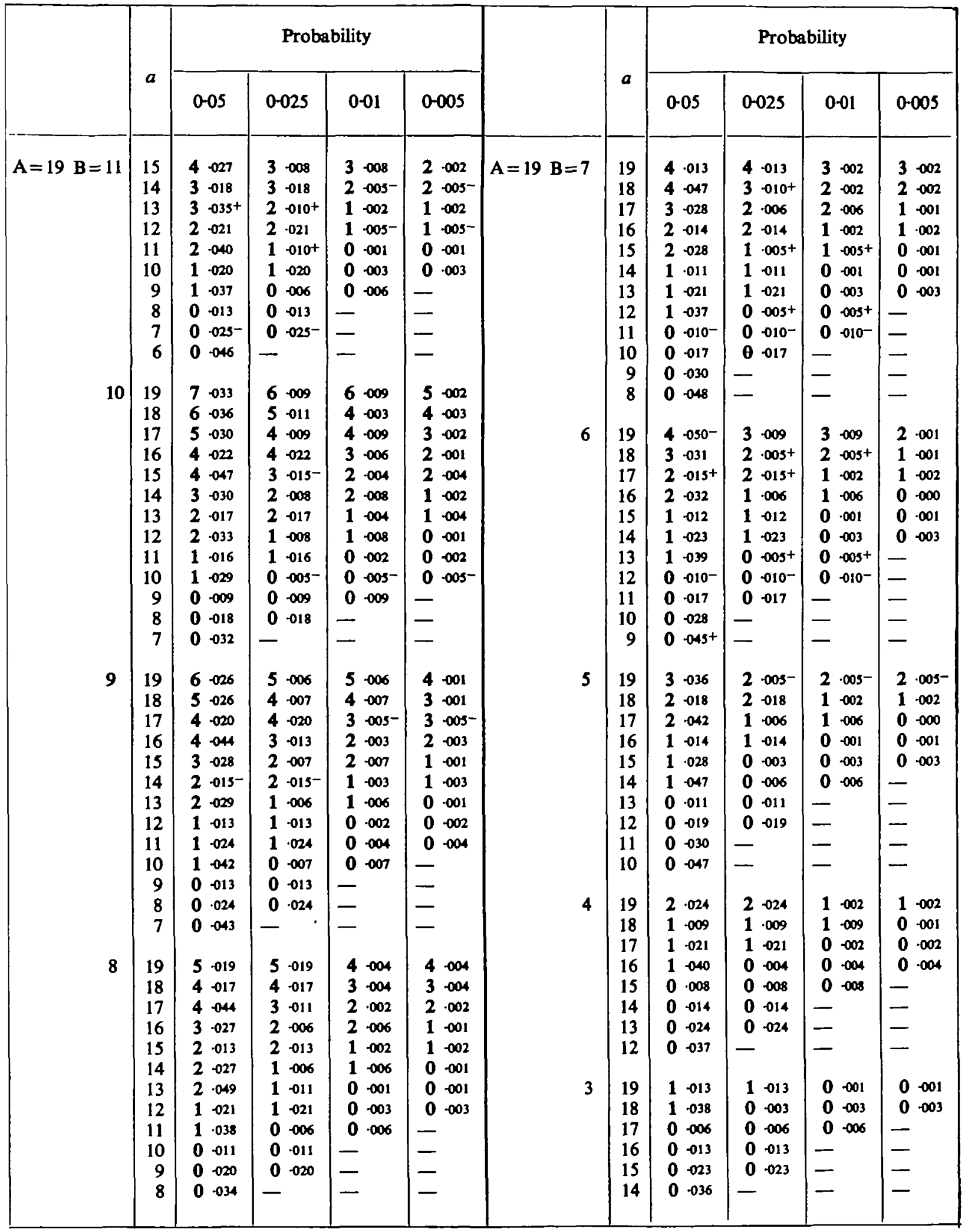


Significance teats in a $8 \times 2$ contingency table (continued)

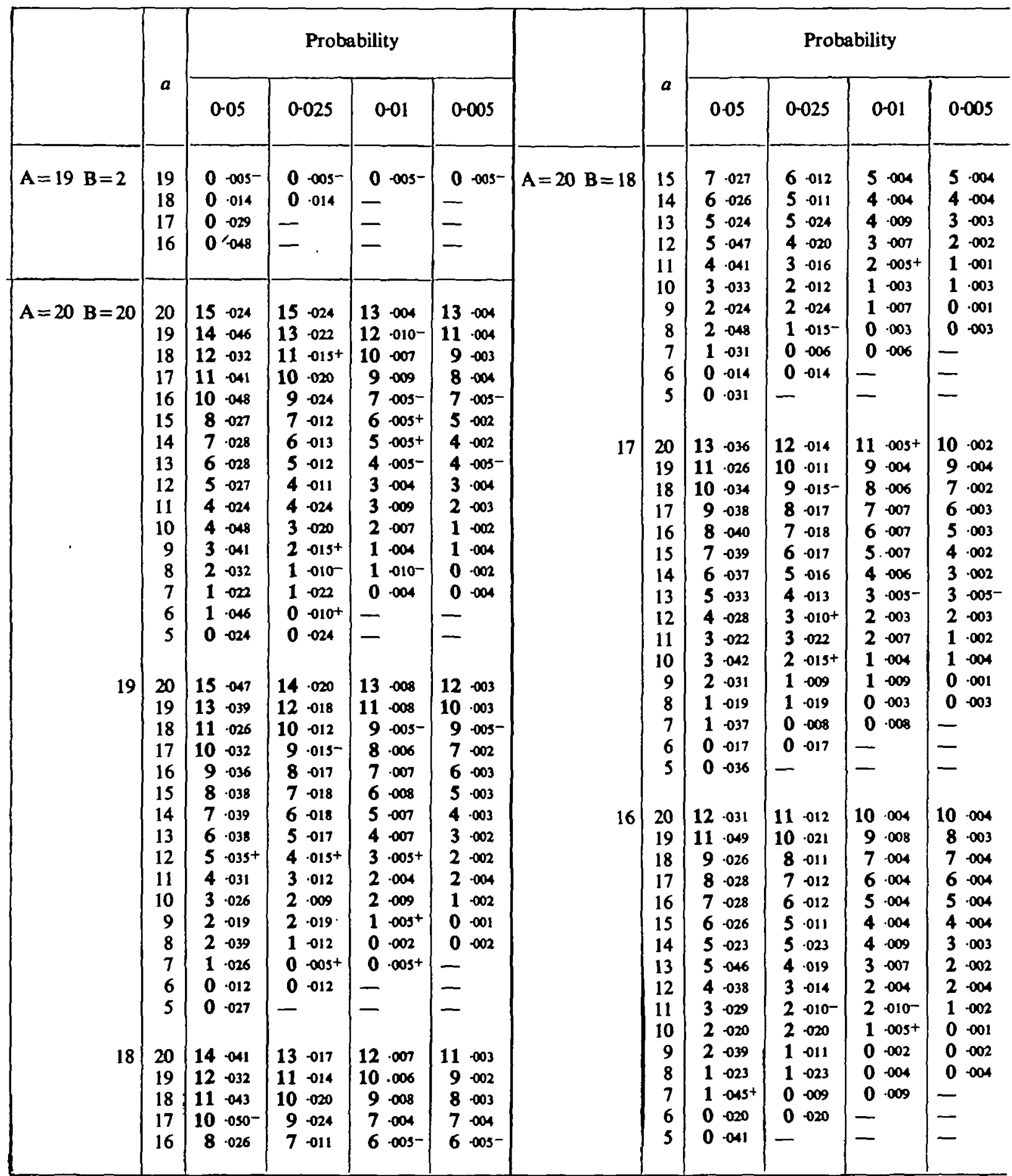

The table shows:

(1) In bold type, for given $A, B$ and $a$, the value of $b(<a)$ which is just significant at the probability leve quoted (single-teil test).

(2) In small type, for given $A, B$ and $r=a+b$, the exact probability (if there is independence) that $b$ is equal tc or less than the integer shown in bold type. 
Signifloance tests in a $2 \times 2$ contingency table (continued)

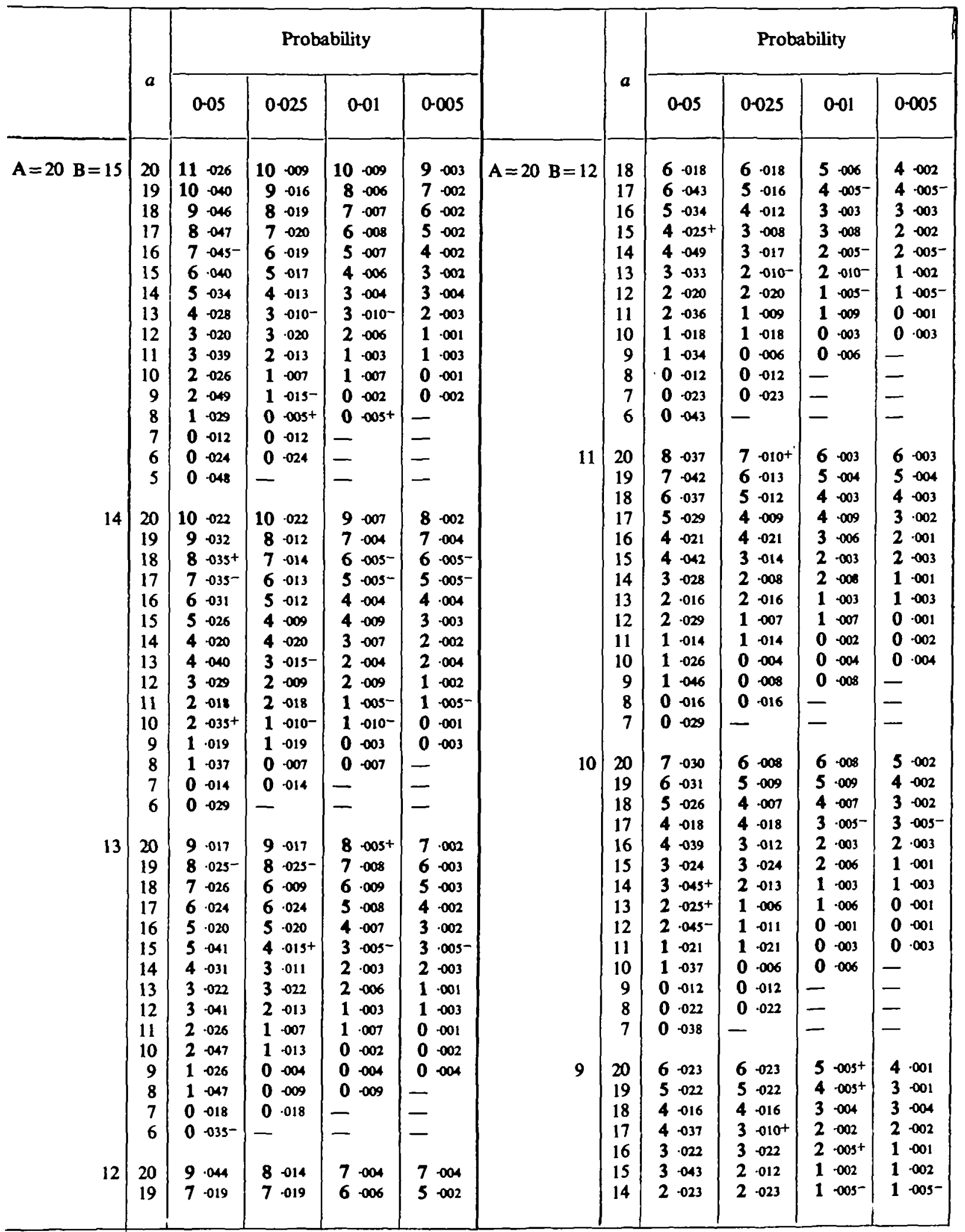


Significance tests in a $2 \times 2$ contingency table (continuad)

\begin{tabular}{|c|c|c|c|c|c|c|c|c|c|c|c|}
\hline & & & Proba & lity & & & & & Prob: & lity & \\
\hline & & 0.05 & 0.025 & $0-01$ & $0-005$ & & & $0-05$ & $0-025$ & $0-01$ & $0-005$ \\
\hline$A=20 \quad B=9$ & $\begin{array}{r}13 \\
12 \\
11 \\
10 \\
9 \\
8 \\
7 \\
20 \\
19 \\
18 \\
17 \\
16 \\
15 \\
14 \\
13 \\
12 \\
11 \\
10 \\
9 \\
8 \\
20 \\
19 \\
18 \\
17 \\
16 \\
15 \\
14 \\
13 \\
12 \\
11 \\
10 \\
9 \\
20 \\
19 \\
18 \\
17 \\
16 \\
15\end{array}$ & 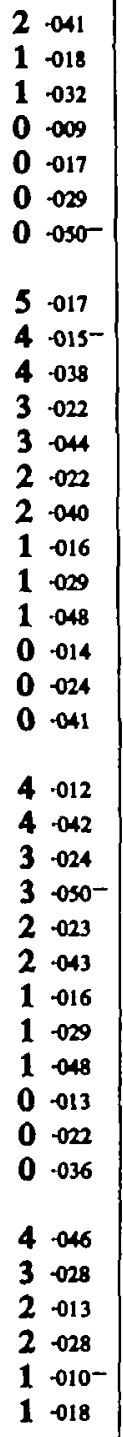 & 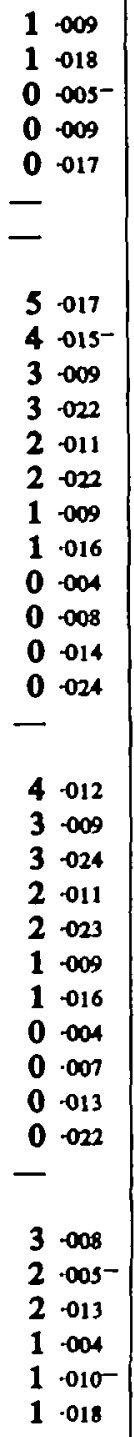 & 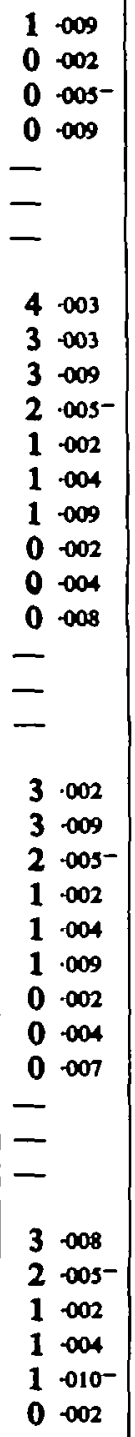 & 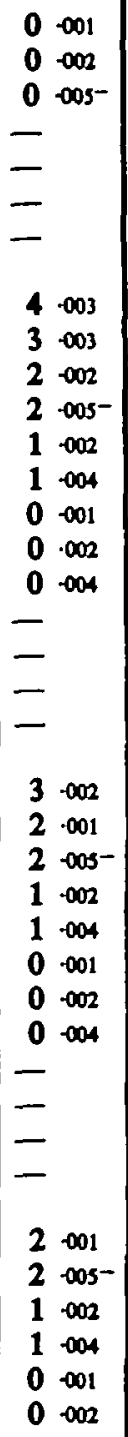 & $A=20 \quad B=6$ & $\begin{array}{l}14 \\
13 \\
12 \\
11 \\
10 \\
\\
20 \\
19 \\
18 \\
17 \\
16 \\
15 \\
14 \\
13 \\
12 \\
11 \\
\\
20 \\
19 \\
18 \\
17 \\
16 \\
15 \\
14 \\
13 \\
12 \\
\\
20 \\
19 \\
18 \\
17 \\
16 \\
15 \\
14 \\
20 \\
19 \\
18 \\
17 \\
20\end{array}$ & $\begin{array}{ll}1 & -032 \\
0 & -007 \\
0 & -013 \\
0 & -022 \\
0 & -035- \\
& \\
3 & -033 \\
2 & -016 \\
2 & -038 \\
1 & -012 \\
1 & -023 \\
1 & -040 \\
0 & -009 \\
0 & -015- \\
0 & -024 \\
0 & -038 \\
& \\
2 & -022 \\
1 & -008 \\
1 & -018 \\
1 & -035 \\
0 & -007 \\
0 & -012 \\
0 & -020 \\
0 & -031 \\
0 & -047 \\
& \\
1 & -012 \\
1 & -034 \\
0 & -006 \\
0 & -011 \\
0 & -020 \\
0 & -032 \\
0 & -047 \\
0 & \\
0 & -004 \\
0 & -013 \\
0 & -026 \\
0 & -043 \\
0 & -048\end{array}$ & 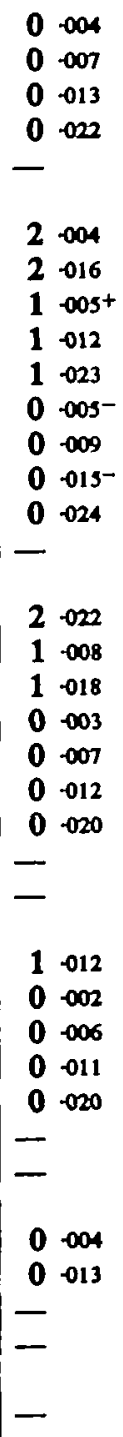 & 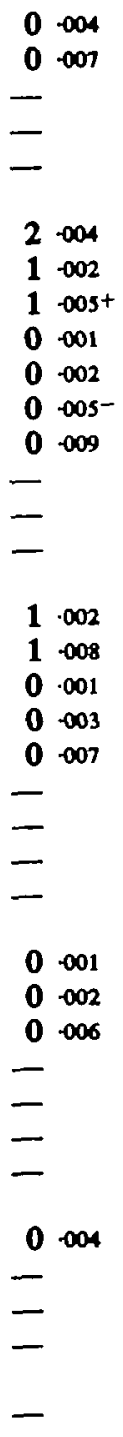 & 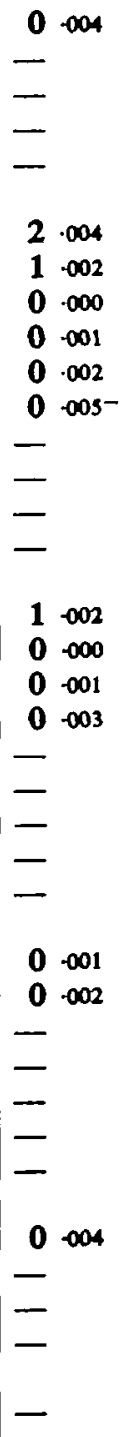 \\
\hline
\end{tabular}

The table shows:

(1) In bold type, for given $A, B$ and $a$, the value of $b(<a)$ which is just gignificant at the probability level quoted (aingle-teil test).

(2) In small type, for given $A, B$ and $r=a+b$, the exact probability (if there is independence) that $b$ is equal to or leses than the integer shown in bold type. 